\title{
Boosting telemedicine through remote monitoring of cardiac electronic devices during the Italian COVID-19 outbreak
}

\author{
Giacomo Mugnai, Andrea Volpiana, Stefano Cavedon, \\ Carla Paolini, Cosimo Perrone, Claudio Bilato \\ Division of Cardiology, West Vicenza General Hospitals, Arzignano (Vicenza), Italy
}

Remote monitoring of cardiac implantable electronic devices (CIEDs) affords an alternative to the one-on-one interaction required in traditional outpatient visits, and provides access to complete information on device performance [1]. The principal purposes of remote monitoring are: to reduce face-to-face hospital visits; ensure continuous follow-up and early detection of device malfunctions and subsequent clinical problems; and provide superior information processing [2].

On 31 December 2019, China reported a cluster of pneumonia cases with unknown etiology to the World Health Organization (WHO), the causative pathogen later being identified as a novel coronavirus (SARS-CoV-2) [3]. On 11 March 2020, WHO declared the pandemic phase of the outbreak [4].

On 20 February 2020, a male admitted to hospital in Codogno (Lombardy, Italy) was confirmed as the first Italian citizen with COVID-19 [5-7]. The following day, a second outbreak was detected, in the Veneto region (Padua). The Government quarantined these two "red" areas by closing schools and commercial activities, and cancelling events. Our public hospital is located west of Vò Euganeo and east of Codogno; i.e., between the two outbreaks.

COVID-19 patients at highest risk for more severe complications and death include people aged $>60$ years and people with comorbidities. Mortality increases with age, with the highest rate among individuals over 80 years of age. Furthermore, mortality is higher among males compared with females. Patients with CIEDs followed by our clini- cal center are of advanced age (mean age $78.5 \pm$ \pm 10.6 years), with more than half $(53.8 \%) 80$ years of age or older (Table 1); most have cardiovascular disease; and there was a higher prevalence of men $(62.7 \% ; \mathrm{n}=570)$. Because the duration of this medical emergency was unknown and the above mentioned clinic population was largely at higher risk of serious consequences from COVID-19 (Table 1), the aim was to check cardiac devices of patients using a home-monitoring system as much as was feasible, thereby reducing outpatient visits and decreasing infection risk for these fragile patients. While the Government was gradually extending restrictions outside of the two red areas, our unit quickly established a new procedure optimizing the management of CIED follow-ups.

Overall, the remote monitoring system covered 909 CIEDs including 678 pacemakers (PMs), 198 implantable cardioverter-defibrillators (ICDs) and 33 loop recorders. The following measures were introduced: first, patients previously refusing device remote monitoring were contacted and strongly encouraged to accept this system. Should they accept, the telemonitoring system was dispatched and activated through a phone-mediated technical support system. Second, all devices without auto-thresholds (i.e., patients without PM-dependency) were exclusively checked through remote monitoring. Third, the new procedure required a mandatory attempt to solve all device alarms via phone communication.

From 3 February to the day preceding the Italian outbreak, 40 patients had CIED monitoring transmissions checked remotely (26 PMs and

Address for correspondence: Giacomo Mugnai, MD, PhD, Division of Cardiology, West Vicenza General Hospitals, Via del Parco 1 - 36071 Arzignano (VI), Italy, tel: +39-0444479106, fax: +39-0444479359, e-mail: mugnai.giacomo@gmail.com

This article is available in open access under Creative Common Attribution-Non-Commercial-No Derivatives 4.0 International (CC BY-NC-ND 4.0) license, allowing to download articles and share them with others as long as they credit the authors and the publisher, but without permission to change them in any way or use them commercially. 
Table 1. Cardiovascular risk factors and comorbidities in the patients overall and comparison between the two samples evaluated between February $3^{\text {rd }}$ and March $9^{\text {th }}$.

\begin{tabular}{|c|c|c|c|c|}
\hline & $\begin{array}{l}\text { Overall patients with } \\
\text { cardiac electronic } \\
\text { devices }(n=909)\end{array}$ & $\begin{array}{c}\text { People evaluated from } \\
\text { February } 3^{\text {rd }} \text { to } \\
\text { February } 20^{\text {th }}(n=88)\end{array}$ & $\begin{array}{l}\text { People evaluated from } \\
\text { February } 21^{\text {st }} \text { to } \\
\text { March } 9^{\text {th }}(n=91)\end{array}$ & $\mathbf{P}$ \\
\hline Age [years] & $78.5 \pm 10.6$ & $80.3 \pm 13.2$ & $79.4 \pm 12.8$ & 0.6 \\
\hline Age $\geq 80$ year-old & $489(54 \%)$ & 45 & 40 & 0.4 \\
\hline Males & $570(63 \%)$ & 55 & 59 & 0.7 \\
\hline Hypertension & $511(56 \%)$ & 48 & 54 & 0.5 \\
\hline Diabetes mellitus & $68(7 \%)$ & 4 & 4 & 0.6 \\
\hline Dyslipidemia & $288(32 \%)$ & 25 & 28 & 0.7 \\
\hline Coronary artery disease & $212(23 \%)$ & 22 & 21 & 0.9 \\
\hline Dilatative cardiomyopathy & $85(9 \%)$ & 10 & 12 & 0.8 \\
\hline Valvular disease & $34(4 \%)$ & 3 & 1 & 0.4 \\
\hline Atrial fibrillation & $373(41 \%)$ & 25 & 30 & 0.5 \\
\hline Chronic heart failure & $139(15 \%)$ & 15 & 21 & 0.4 \\
\hline Chronic kidney disease* & $177(19 \%)$ & 17 & 16 & 0.8 \\
\hline COPD & $55(6 \%)$ & 3 & 5 & 0.7 \\
\hline
\end{tabular}

${ }^{*}$ Glomerular filtration rate $<50 \mathrm{~mL} / \mathrm{min} / \mathrm{m}^{2}$; COPD — chronic obstructive pulmonary disease

Table 2. Patients with cardiac implantable electronic devices managed via face-to-face outpatient visits or remote monitoring during two equivalent time frames: before and after 20 February 2020 (Day 0 of the Italian COVID-19 outbreak).

\begin{tabular}{lccc}
\hline & Before Day 0 (n = 84) & After Day 0 (n=83) & Difference, N (\% change) \\
\hline Outpatient visits & $44(52.4 \%)$ & $25(30.1 \%)$ & $-19(-43.2 \%)$ \\
Remote monitoring & $40(47.6 \%)$ & $58(69.9 \%)$ & $+18(+45.0 \%)$ \\
\hline
\end{tabular}

14 ICDs), whereas 44 underwent checks face-to-face (Table 2). Among these face-to-face checks, 17 were for clinical evaluation of the device pocket/ /wound after PM/ICD implantation/replacement, 9 were electronic checks for devices unsuited to home monitoring, 4 were checks of remaining battery life, 4 were in patients who had previously refused home monitoring, 6 in patients with suspected device malfunctioning, and 4 for ICDs without an auto-threshold. In the same period, 4 alerts were received: 2 in patients with new-onset atrial fibrillation (AF) and 2 in patients with abnormal sensing of the ventricular lead. These patients were all managed through in-hospital consultations.

In an equivalent time frame following the COVID-19 outbreak, from 21 February (when the new procedure was activated) and up to 9 March, the total CIED transmissions checked remotely was 58 (40 PMs and 18 ICDs) and the number of face-to-face outpatient visits was 25, including 15 clinical evaluations of the wound/pocket after de- vice implantation/replacement and 10 checks of old PMs without a remote monitoring option (Table 2). In-office checks were avoided in 9 patients (5 received the remote monitoring device at home, 4 had ICDs without an auto-threshold). During this period, 8 non-urgent alerts were received: 2 sinus pauses detected by loop recorders (these were already known about; no intervention needed), 1 inappropriate shock (the patient was instructed by phone to increase their beta-blocker dose), 2 cases of a low percentage of biventricular stimulation in cardiac resynchronization devices (no intervention required; these patients were already waiting for atrioventricular node ablation), 1 case of low sensing of the ventricular lead (we knew of this; the patient was in follow-up), and 2 new cases of $\mathrm{AF}$. Among the 2 latter patients, one needed urgent evaluation for initiation of oral anticoagulation and the other, who had a dual-chamber PM and a history of recurrent episodes of $\mathrm{AF}$, required pharmacotherapy modification; their prescription 
was electronically sent to the pharmacy, avoiding travel to the hospital. Actually 5 out of 8 non-urgent alerts were "already-known" problems, therefore they were more easily managed through phone calls, thus avoiding in-office checks.

In summary, the application of the new procedure following the Italian COVID-19 outbreak resulted in a robust $43.2 \%$ decrease in the need for outpatient checks conducted face-to-face. Notably, all the alerts except one were managed through phone communication. At the same time, remote monitoring increased markedly, by $45 \%$.

Although comprising a small sample of patients and of short duration, this study demonstrates that a simple modified approach might be helpful for reducing in-office checks in patients with CIEDs, preserving the safety and efficiency of the whole monitoring system. This appears important in the current COVID-19 pandemic emergency, where reducing the number of new cases per unit of time is essential. Minimizing travel and hospital/ /outpatient clinic admissions for patients may markedly reduce the spread of COVID-19, especially if adopted by all hospitals for a prolonged duration, particularly those with high patient volumes. Furthermore, remote monitoring could be highly valuable for patient management and follow-up, in general. It reduces the number of face-to-face visits required - saving patients' time and expense - and, thanks to continuous follow-up and early detection of device malfunctions, improves safety and quality of life.

\section{Acknowledgements}

We would like to thank Maria Chiara Corti, $\mathrm{MD}, \mathrm{PhD}$, MHS for her helpful advice, and Gayle Robins, independent medical writer, for medical writing support on behalf of Health Publishing
Services (HPS). This unconditional support was funded by Novartis Farma.

Conflict of interest: None declared

\section{References}

1. Hernández-Madrid A, Lewalter T, Proclemer A, et al. Remote monitoring of cardiac implantable electronic devices in Europe: results of the European Heart Rhythm Association survey. Europace. 2014; 16(1): 129-132, doi: 10.1093/europace/eut414, indexed in Pubmed: 24344325.

2. Zanotto G, Melissano D, Baccillieri S, et al. Intrahospital organizational model of remote monitoring data sharing, for a global management of patients with cardiac implantable electronic devices: a document of the Italian Association of Arrhythmology and Cardiac Pacing. J Cardiovasc Med (Hagerstown). 2020; 21(3): 171-181, doi: 10.2459/JCM.0000000000000912, indexed in Pubmed: 32004241.

3. $\mathrm{Wu} Z$, McGoogan JM. Characteristics of and important lessons from the coronavirus disease 2019 (COVID-19) outbreak in China: summary of a report of 72314 cases from the Chinese center for disease control and prevention. JAMA. 2020; 323(13): 1239-1242, doi: 10.1001/jama.2020.2648, indexed in Pubmed: 32091533.

4. World Health Organization. Director-General's opening remarks at the media briefing on COVID-19 - 11 March 2020. https:// www.who.int/dg/speeches/detail/who-director-general-s-opening-remarks-at-the-media-briefing-on-covid-19---11-march-2020 (Accessed 08 May 2020).

5. Spina S, Marrazzo F, Migliari M, et al. The response of Milan's Emergency Medical System to the COVID-19 outbreak in Italy. Lancet. 2020; 395(10227): e49-e50, doi: 10.1016/s01406736(20)30493-1.

6. Carinci F. Covid-19: preparedness, decentralisation, and the hunt for patient zero. BMJ. 2020; 368: bmj.m799, doi: 10.1136/bmj. m799, indexed in Pubmed: 32111645.

7. Grasselli G, Pesenti A, Cecconi M. Critical care utilization for the COVID-19 outbreak in lombardy, italy: early experience and forecast during an emergency response. JAMA. 2020; 323(16): 1545-1546, doi: 10.1001/jama.2020.4031, indexed in Pubmed: 32167538 . 